\title{
UNIDADES FRASEOLÓGICAS IDIOMÁTICAS NO LIVRO DIDÁTICO "PANORAMA BRASIL": UMA ANÁLISE A PARTIR DE CONTRIBUIÇÕES DA PSICOLINGUÍSTICA PARA O ENSINO
}

\author{
Narjara Oliveira REIS ${ }^{1}$ \\ Universidade Federal de Santa Catarina (UFSC) \\ Coordenação de Aperfeiçoamento de Pessoal de Nível Superior (CAPES) ${ }^{2}$ \\ (jarareis@gmail.com)
}

\begin{abstract}
Resumo: Considerando a abundância de unidades fraseológicas idiomáticas (UFIs) na interação do brasileiro e a importância que os materiais didáticos têm para professores e alunos na mediação do processo de aprendizagem, procurou-se analisar as potencialidades do livro "Panorama Brasil: ensino do português do mundo dos negócios" para ao ensino de UFIs de acordo com autores que apontam métodos ancorados em achados da Psicolinguística. Como conclusão do estudo, o material demonstrou ter um desenho adequado para a apresentação das UFIs carecendo, porém, de atividades que favoreçam a fixação dessas unidades pela memória de longo prazo, segundo orientam Durão e Andrade (2009), Lahuerta e Pujol (1993; 1996) e outros.
\end{abstract}

Palavras-chave: unidades fraseológicas idiomáticas; português para estrangeiros; materiais didáticos.

Abstract: Considering the expressive number of idioms in brazilian people interaction and the importance teaching materials have for students and teachers in the language learning process, this research aims to analyse the potential of "Panorama Brasil: ensino do português do mundo dos negócios" related to the teaching of idioms according to Psycholinguistic findings. As a result, the material showed a good design for the moments of presentation of idioms, but the same can't be said in what concerns for those of memory retaining of these lexical items as suggested by Durão \& Andrade (2009), Lahuerta \& Pujol (1993; 1996) and others.

Keywords: idioms; portuguese as a second language; teaching materials.

Resumen: Las unidades fraseológicas idiomáticas (UFIs) son abundantes unidades léxicas en el uso oral y escrito de la lengua portuguesa por brasileños. En el processo de aprendizaje de una lengua extranjera, los materiales didácticos suelen ser importantes instrumentos de mediación entre los aprendices, el profesor y los conocimientos. Por eses motivos, la presente investigación analisa las potencialidades del libro "Panorama Brasil: ensino do português do mundo dos negócios" en lo que se refiere al ensino de UFIs em consonancia con autores que parten de las aportaciones de la lingüística y de la psicolingüística para reflexionar sobre la enseñanza de las UFIs. El análisis reveló un dibujo favorable a la apresentación de las UFIs, pero careció de actividades que estimulasen la retención de esas unidades léxicas por la memoria a largo plazo, según orientaciones de Durão y Andrade (2009), Lahuerta y Pujol (1993; 1996), y otros.

Palavras clave: unidades fraseológicas idiomáticas; portugués para extranjeros; materiales didácticos.

\section{INTRODUÇÃO}

\footnotetext{
${ }^{1}$ Doutoranda em Linguística do Programa de Pós-Graduação em Linguística da Universidade Federal de Santa Catarina (PPGLin-UFSC).

2 O presente trabalho foi realizado com apoio da Coordenação de Aperfeiçoamento de Pessoal de Nível Superior - Brasil (CAPES) - Código de Financiamento 001.
} 


\section{("tifrer}

Para adquirir uma ou mais línguas orais não é necessário desenvolver habilidades conscientemente. Segundo a perspectiva inatista, basta ser dotado biologicamente da faculdade da linguagem e de recursos naturais que possibilitem o feito - ser ouvinte e não possuir danos nas estruturas da memória, por exemplo. Essas seriam condições inerentes a todos os seres humanos ouvintes saudáveis (CHOMSKY, 1998, p.17). Entretanto, além da disponibilidade cognitiva para memorização (DURÃO; ANDRADE, 2009), seria necessária a imersão em um meio linguístico.

De modo análogo, para aprender uma língua estrangeira oral (LE) e apropriar-se dos significados que nela circulam através do seu léxico, é necessária a memória. Também é preciso ter disponível o aparelho fonológico para a realização dos fonemas com os traços adequados para marcar as distinções de sentido (pelo menos de modo aproximado que permita a desambiguação). Contudo, nem sempre é necessária a imersão ${ }^{3}$.

De modo oposto ao que ocorre na aquisição de forma natural, na aprendizagem, a depender do momento e do local em que se aprende a língua, são necessários esforços conscientes para compreender as distintas situações de uso da língua e para ter segurança sobre quando e como utilizá-la. Em contextos formais, as questões extralinguísticas, adquiridas implicitamente no primeiro caso, muitas vezes, precisam ser "declaradas", ou seja, precisam ser explicadas para que o aluno compreenda como certas estruturas fazem sentido na configuração cultural associada à língua-alvo de aprendizagem.

No que diz respeito aos itens léxicos objeto de investigação deste trabalho, as unidades fraseológicas idiomáticas (UFIs), mais comumente conhecidas como "expressões idiomáticas", a carga metafórica que carregam, a estrutura específica que constituem e a importância que sua aprendizagem tem para a inserção do estrangeiro na apreensão e na produção de sentidos na comunidade brasileira merece atenção especial do professor de Português para Estrangeiros. Considera-se que apreender as camadas de sentido que revestem as UFIs poderá habilitar o estudante a traduzir 3 Imersão refere-se ao contato prolongado com uma comunidade de pessoas que usam a língua-alvo
de modo fluente. 


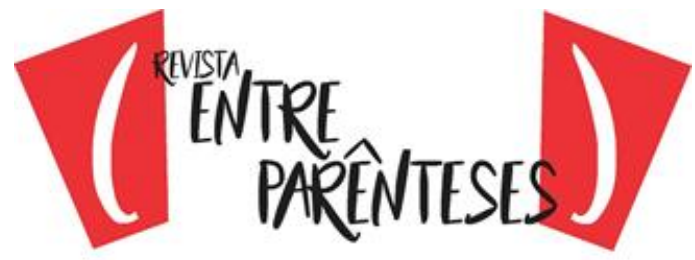

pragmaticamente o mundo na língua-alvo. Nesse sentido, é de grande auxílio o feedback que outros interlocutores podem fornecer aos aprendizes, sejam nas figuras de transeuntes em contexto de imersão, de colegas em sala de aula de língua portuguesa, mas também através dos materiais didáticos.

No contexto formal de ensino, o material didático tem um valor especial para professores e alunos. É ainda uma das principais ferramentas envolvidas na atividade docente. Como reunião de textos, atividades, informações gramaticais e outros elementos que dão suporte ao processo de ensino, ainda que possua suas imperfeições e limites, é obra auxiliar e, portanto, justifica-se a consideração crítica de sua constituição para que sejam exploradas suas potencialidades e complementadas suas fragilidades.

Compreende-se que o caráter social da linguagem permeia os sentidos dos enunciados proferidos pelos sujeitos de uma dada comunidade de fala nas distintas esferas em que se articula a interação (BAKHTIN, 2010, p. 46). Portanto, deve ser considerado e evidenciado em materiais didáticos (REIS, 2016). Deste modo, o aprendiz estrangeiro poderá vivenciar a língua-cultura que está a aprender em contraste e diálogo com a própria língua-cultura ${ }^{4}$, apreendendo de forma mais profunda seus significados.

Neste artigo, pretende-se refletir sobre a presença de UFIs no livro didático "Panorama Brasil: ensino do português do mundo dos negócios" (PONCE, 2006a). Além disso, também serão abordados aspectos relativos ao ensino dessas lexias, utilizando autores que estudam o léxico ancorados em contribuições da Psicolinguística para o ensino de línguas.

O artigo está organizado em três seções intituladas Unidades fraseológicas idiomáticas e o ensino, Análises, Discussão e uma seção conclusiva.

\section{UNIDADES FRASEOLÓGICAS IDIOMÁTICAS E O ENSINO}

\footnotetext{
4 É válido considerar a perspectiva intercultural do ensino de línguas, visão que considera o aluno um interlocutor ativo e responsivo, dotado de uma língua-cultura particular e de uma subjetividade singular. Para melhores considerações sobre o assunto, consultar Mendes (2010, p. 53-77).
} 


\section{("titrere}

As UFIs caracterizam-se morfologicamente por funcionarem como um bloco unitário de significado, podendo ser classificadas como transparentes, quando seu sentido é facilmente deduzido pelos itens lexicais que as constituem, ou opacas, quando seu sentido não pode ser facilmente deduzido (DURÃO; EL-HASSANI, 2005, p. 114).

Experimentos na área da Psicolinguística Experimental definem UFIs como blocos unitários de sentido, pois o tempo de processamento dessas unidades lexicais seria equivalente ao de lexias simples, ou seja, as UFIs seriam apreendidas/compreendidas como um bloco semântico único e não como um conjunto de itens léxicos com significados independentes - sejam elas transparentes ou opacas (CUTLER, 1983; GIBBS, GONZALES, 1985; SWINNEY; CUTLER, 1979). Segundo essa perspectiva, quando um indivíduo interpreta uma UFI como "chutar o balde", o tempo de processamento do significado é menor do que seria se os itens léxicos aparecessem sem a carga metafórica, ou seja, se o sentido fosse literal. Neste caso, o processamento se daria de forma mais longa, ativando o sentido de uma ação em que um balde é chutado. No sentido literal, no entanto, a sentença pressupõe um sujeito agente, um verbo que explicita a ação de chutar e um paciente "chutado". No caso da UFI, o sentido não literal seria equivalente ao verbo intransitivo "desistir", que possui um sujeito, porém não possui complemento. Segundo Swinney, Cutler (1979), Cutler (1983) e Gibbs e Gonzales (1985), a UFI teria uma estrutura menos complexa que a justaposição de seus itens léxicos em sentido literal.

Como consequência, do ponto de vista pedagógico, alguns autores ancorados em achados da Psicolinquística Experimental, têm sugerido que as UFIs devam ser ensinadas também como um bloco unitário de sentido, referindo-se a elas como unidades e não como agrupamento de itens léxicos individuais e independentes (CHANNEL, 1988; GARCÍA, 2003; LAHUERTA; PUJOL, 1993, 1996; McCARTHY, 1990;). Por este motivo, rejeitam o uso pedagógico de listas de UFls organizadas a partir de um item léxico comum, quando o significado for diferente, já que esse fato interfere na motivação semântica da aprendizagem de novos itens lexicais pelo léxico mental (AITCHISON, 1987). No caso da língua portuguesa, por exemplo, não justificaria reunir as seguintes UFIs com a justificativa de todas possuírem um mesmo 


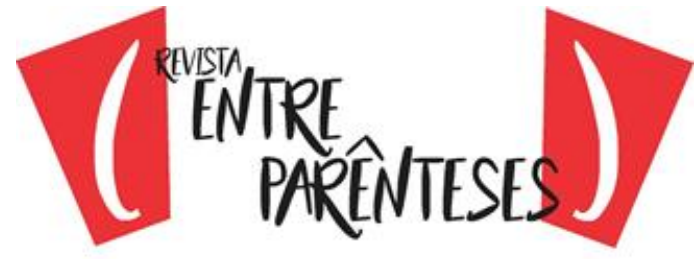

item léxico: "ser a bola da vez", "pisar na bola"e "comer a bola", já que cada um desses agrupamentos se refere a um sentido distinto: "estar em evidência" (SILVEIRA, 2010, p. 757-758), "cometer um engano" (SILVEIRA, 2010, p. 687), "fazer excelente exibição"(SILVEIRA, 2010, p. 164), respectivamente. Assim, a recomendação desses autores é a de que as UFIs sejam introduzas separadamente e em contexto favorável à sua compreensão, com foco no sentido, portanto e não na forma (GAIRNS; REDMAN, 1986; GARCIA, 2003; GURILLO, 2000).

Além do aspecto semântico relacionado ao ensino, Channel (1988) também chama atenção para a ênfase necessária ao aspecto fonológico, mais especificamente à pronúncia e à sílaba tônica. $\mathrm{A}$ autora assim o faz porque achados da Psicolinguística sugerem que a organização do léxico mental é fortemente motivada tanto pelo aspecto semântico quanto pelo fonológico (AITCHISON, 1987) ${ }^{5}$. Análises de slips of the tongue (literalmente, deslizes da língua, quando se quer dizer $x$ mas se diz $y$ ) realizados por adultos não acometidos por patologias levaram a supor que aspectos fonológicos (como a sílaba tônica) e semânticos (como a troca de um item por outro dentre um conjunto de eletrodomésticos) têm um papel central na organização do léxico mental (AITCHISON, 1987). Esses dados são reforçados por estudos com afásicos e trabalhos de linguistas teóricos. O léxico mental, de modo simplista, seria o conjunto de itens lexicais disponíveis para uso na mente de um usuário da língua. Sua constituição se daria através de uma rede de sentidos que se fortalece a cada novo contato com a unidade lexical em questão (AITCHISON, 1987).

No que diz respeito à memorização desses itens lexicais, Durão e Andrade (2009) salientam que a atenção ao conteúdo novo deve ser estimulada de várias maneiras (auditiva, oral, visual) para possibilitar condições de retenção do estímulo. Lahuerta e Pujol $(1993,1996)$, que partilham da mesma visão, postulam que três momentos devem ser considerados quando do ensino de UFIs: o momento de compreensão, o momento de retenção e o momento de produção. No primeiro deles, no momento de compreensão, é necessário que se dê a chance de os aprendizes se esforçarem para a realização de associações sem ajuda do professor, assim, seriam estimuladas as conexões que favorecem a memorização para a criação de novas 


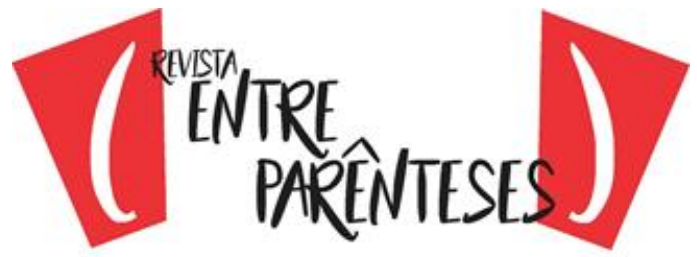

redes de sentido (DURÃO; ANDRADE, 2009; CHANNEL, 1988). Dentro de um dado contexto (um texto, por exemplo), a UFI pode ser realçada para que $o$ aluno busque $o$ significado a partir de elementos contextuais. Além de evitar o agrupamento de UFIs em listas em que apareçam descontextualizadas, orienta-se também a não apresentação de várias UFIs ao mesmo tempo, uma vez que a associação semântica não seria favorecida. De maneira geral, indicam que é mais favorável a apresentação de um item várias vezes que a de vários itens de uma vez só.

Após o momento de compreensão, é preciso haver condições para o momento de retenção da UFI, que pressupõe um contato intensivo com o item lexical. Para isso, o professor pode chamar a atenção do(s) aprendiz(es) para aspectos fonológicos, além de demonstrar outros contextos em que a utilização da estrutura é adequada e, em seguida, orientar atividades de produção oral e escrita, em que o aluno é desafiado a utilizar a UFI. Coloca-se uma ênfase ao que o professor pode fazer porque essa investigação busca contribuir para o contexto formal e mediado de ensino. Claro é que o aluno pode buscar por meios próprios estimular a retenção de UFIs a partir do uso repetido de tais estruturas em suas interações e produções ou da procura por textos em que tal item léxico aparece através de ferramentas de busca virtuais, por exemplo. Essas atitudes podem ser, inclusive, incentivadas para incentivar a autonomia de aprendizagem do aluno.

O terceiro e último momento é o de produção em que, uma vez retida, a UFI se torna parte do repertório léxico do aprendiz (por um dado tempo e de acordo com a capacidade cognitiva do indivíduo). No entanto, é importante diferenciar a produção oral e escrita do "momento de produção" a que se referem os autores citados. Esse momento diz respeito à disponibilidade de dado item no repertório léxico para produção, ou seja, quer dizer que foram realizadas tantas associações ao item no repertório mental do aprendiz a ponto de tê-lo tornado disponível na memória de longo prazo para uso em outros momentos que não o imediatamente após sua aprendizagem. Ou seja, difere do sentido de produção oral ou escrita que pode ser motivada pela simples repetição e uso da memória de curto prazo, por exemplo e não pela apreensão propriamente dita do item em questão (DURÃO; ANDRADE, 2009). 


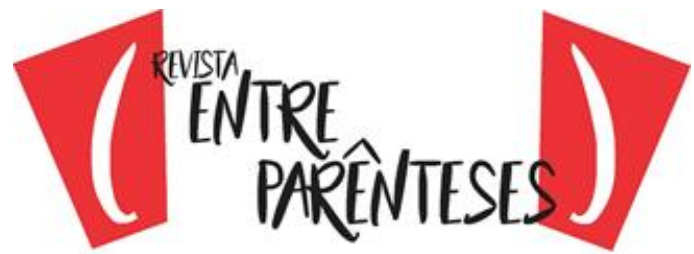

Estudos sugerem que a retenção de um item léxico exige um contato significativo e variado com a unidade lexical (DURÃO; ANDRADE, 2009). Deste modo, seriam necessários vários momentos de experiência com dado item para a sua apreensão. Lahuerta e Pujol (1996) afirmam ainda que a falta de uso dos itens léxicos apreendidos está associada ao desaparecimento destes na memória de longo prazo.

Uma das dificuldades no que diz respeito ao ensino e à aprendizagem lexical, segundo essa visão, é a de avaliar se as unidades léxicas foram aprendidas ou não. Pois, ainda que os esforços didáticos sejam feitos para permitir os três momentos envolvidos na aprendizagem lexical, não se pode garantir que depois de realizados um número $x$ de atividades, elas venham a ser retidas. Ainda assim, esses conhecimentos podem servir para que o professor valorize os momentos de repetição, revisão de itens lexicais já tratados e de reconsideração dos mesmos em outros contextos, já que assim parece proceder a apreensão do conhecimento: por redes de sentido que se formam e se fortalecem com o uso variado e significativo (DURÃO; ANDRADE, 2009).

Essa classificação em diferentes momentos de aprendizagem é baseada em evidências da Psicolinguística de que a aprendizagem de qualquer elemento se dá a partir da criação de uma rede em que informações antigas se unem a novas, formando teias de sentido (CHANNEL, 1988; LAHUERTA; PUJOL, 1993, 1996).

A partir das considerações feitas por diversos autores que propõem metodologias de ensino baseadas em achados da Psicolinguística, foi gerada uma Matriz da Análise para ser aplicada às atividades propostas pelo livro didático (cf. Tabela 1).

Tabela 1 - Matriz de Análise - Implicações para o Ensino de Vocabulário e de UFIs

\begin{tabular}{|l|l|}
\hline Durão; Andrade (2009) & $\begin{array}{l}\text { - A atenção ao conteúdo novo deve ser estimulada de várias maneiras } \\
\text { (auditiva, oral) para que haja condições de o estímulo ser retido na } \\
\text { memória de curto prazo; } \\
\text { - As novas unidades léxicas devem ser associadas ao conhecimento } \\
\text { prévio para que possa haver retenção na memória de longo prazo. }\end{array}$ \\
\hline Channel (1988) & - Eeve haver momentos específicos para o ensino de vocabulário; \\
& - Encorajame no aspecto fonológico (pronúncia e sílaba tônica); \\
& - Conexões do tipo semântico (apresentações baseadas no uso de \\
& campos semânticos).
\end{tabular}




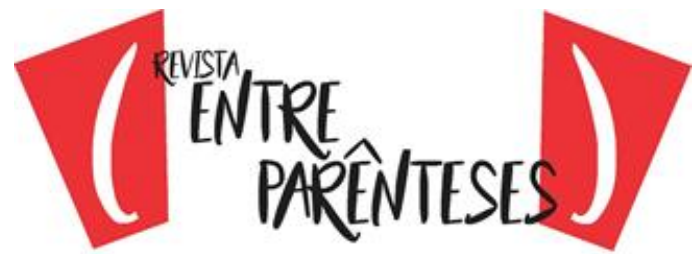

\begin{tabular}{|c|c|}
\hline $\begin{array}{l}\text { Lahuerta; Pujol (1993; } \\
\text { 1996) }\end{array}$ & $\begin{array}{l}\text { - Deve-se ensinar a compreender mensagens e a inferir significados; } \\
\text { - Não pedir a memorização, mas sugerir meios que a favoreçam; } \\
\text { - Incorporar a utilização das novas unidades léxicas, indicar meios para } \\
\text { favorecer o uso significativo; } \\
\text { - Favorecer marcos que ativem o léxico mental a partir do contexto/criar } \\
\text { um ambiente de associações que prepare a rede para a nova unidade } \\
\text { léxica; } \\
\text { - Em exercícios de compreensão: as imagens podem auxiliar a produzir } \\
\text { hipóteses sobre o texto verbal; } \\
\text { - Ensino de unidades léxicas previamente à leitura é uma alternativa; } \\
\text { - Utilizar estímulos vários para a apresentação do vocabulário: mímica, } \\
\text { onomatopeia, gesto, sinonímia, antonímia, exemplificação com frases ou } \\
\text { situações e a explicação; } \\
\text { - Utilizar a associação fonética de um item da L1 a outro da L2 através } \\
\text { de imagens; } \\
\text { - Fazer associações semânticas; } \\
\text { - Evitar o uso de listas de itens léxicos; } \\
\text { - Evitar a exposição de um grande número de unidades léxicas novas } \\
\text { por vez; } \\
\text { - Estimular a utilização da unidade léxica nas primeiras } 24 \mathrm{~h} \text {, para } \\
\text { favorecer a retenção; }\end{array}$ \\
\hline McCarthy (1990) & $\begin{array}{l}\text { - Propiciar a apresentação da unidade léxica em meio a informações } \\
\text { contextuais necessárias para o uso adequado das unidades. }\end{array}$ \\
\hline $\begin{array}{l}\text { Penadés } \\
(1999)^{6}\end{array}$ & $\begin{array}{l}\text { - Uso do dicionário como instrumento de seleção de unidades léxicas; } \\
\text { - Inserção das UFIs desde os primeiros níveis; } \\
\text { - Apresentação das características das UFls: a idiomaticidade, a } \\
\text { - O profacessonor deuve formular um exemplo-base simples, forma abstraída } \\
\text { - da UFI; } \\
\text { - Formação de listas de UFIs motivada por áreas temáticas: utilizando } \\
\text { um item lexical componente comum às UFIs }{ }^{7} \text {; } \\
\text { - Aplicar exercícios para verificar a compreensão das unidades léxicas. }\end{array}$ \\
\hline Gurillo (2000) & $\begin{array}{l}\text { - As UFIs não devem ser inseridas nos primeiros níveis; } \\
\text { - O livro-texto deveria constituir um apoio mais firme na sala de aula; } \\
\text { - Evitar a inserção de atividades motivadas por um item lexical comum } \\
\text { a todas as UFIs; } \\
\text { - Não tratar as UFIs como uma combinação livre de palavras; } \\
\text { - Indicar os contextos de uso adequados nos quais empregar as UFIs; } \\
\text { - Mencionar nos materiais de ensino que unidades léxicas idiomáticas } \\
\text { estão em desuso. }\end{array}$ \\
\hline García (2003) & $\begin{array}{l}\text { - Não se deve escolher um item léxico temático; } \\
\text { - A relação a ser enfatizada deve ser semântica; } \\
\text { - Tratamento de unidades léxicas como itens individuais não } \\
\text { desmembráveis; } \\
\text { - Direcionar a aprendizagem para itens que sejam úteis ao aprendiz; } \\
\text { - Elaborar glossários nivelados; } \\
\text { - Agrupar UFls semanticamente motivadas; }\end{array}$ \\
\hline
\end{tabular}

${ }^{6}$ É interessante verificar como a maioria dos autores concorda com o não agrupamento de UFIs para o ensino. Ao contrário de Penadés Martinez (1999) que discorda, sugerindo que se devam reuni-las. Porque compreende-se que a motivação semântica é primordial, decidiu-se não aplicar as sugestões desta autora como mais favoráveis a aprendizagem.

7 Não aplicado. 


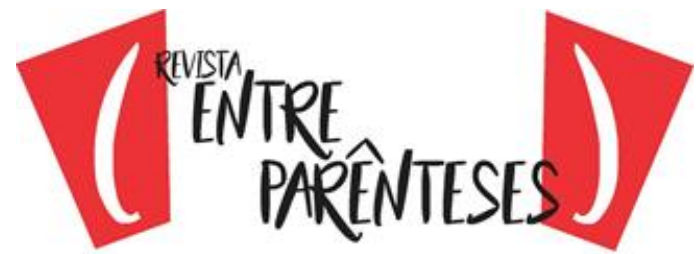

\begin{tabular}{|c|c|}
\hline & $\begin{array}{l}\text { - Escolher as UFIs mais transparentes para os níveis mais baixos e as } \\
\text { mais opacas, para os mais altos; } \\
\text { - Junção dos critérios lexical e semântico para a elaboração de } \\
\text { glossários nivelados; } \\
\text { - Integrar as UFIs em campos semânticos; } \\
\text { - Recorrer ao mapa conceitual evocado pelos itens léxicos; } \\
\text { - Utilizar frases-tipo, apresentação do significado e usos são } \\
\text { importantes em um primeiro momento, mas deve-se enfocar no } \\
\text { encaminhamento do aluno à formação de conceitos; } \\
\text { - A introdução das unidades léxicas deve respeitar as fases de entrada, } \\
\text { armazenamento e recuperação. }\end{array}$ \\
\hline Gairns; Redman (1986) & $\begin{array}{l}\text { - Tratar as unidades léxicas como itens individuais não desmembráveis; } \\
\text { - Direcionar a aprendizagem para itens que sejam úteis ao aprendiz. }\end{array}$ \\
\hline Pavlenko (2009) & $\begin{array}{l}\text { - Equivalência conceitual facilita a aprendizagem através da } \\
\text { transferência positiva; } \\
\text { - Estabelecer ligações entre as unidades léxicas da L2 e conceitos pré- } \\
\text { existentes; } \\
\text { - Estimular a reestruturação conceitual para não equivalências; } \\
\text { - Desenvolver novas categorias linguísticas que possam permitir ao } \\
\text { aprendiz o mapeamento conceitual de unidades léxicas novas. }\end{array}$ \\
\hline
\end{tabular}

A maioria dos autores estudados concorda com os critérios de motivação semântica e fonológica para reunião e tratamento da UFIs, exceto Penadés Martinez (1990), a qual sugere que possam ser feitas listas motivadas por um item lexical comum às UFIs - critério que não foi aplicado à análise.

A estrutura geral do livro didático foi detalhada abaixo e, em seguida, foram realizadas as análises e a discussão dos resultados.

\section{ANÁLISES}

\section{O livro didático (LD) Panorama Brasil: o ensino de português do mundo} dos negócios (PONCE; BURIM; FLORISSI, 2006a) destaca-se dentre os LDs de língua portuguesa destinados ao público estrangeiro. Isso porque encontra-se número abundante de UFIs em textos e atividades, tendo sido este o motivo pelo qual foi escolhido para análise pormenorizada.

O propósito do LD Panorama Brasil é apresentar o mundo dos negócios, salientando o vocabulário utilizado em diversos ambientes de trabalho (PONCE; BURIM; FLORISSI, 2006a, p. 7). As unidades são distribuídas por tema (e não por tópico gramatical) em 10 capítulos: Agronegócios, Tecnologia, Arte e Cultura, 


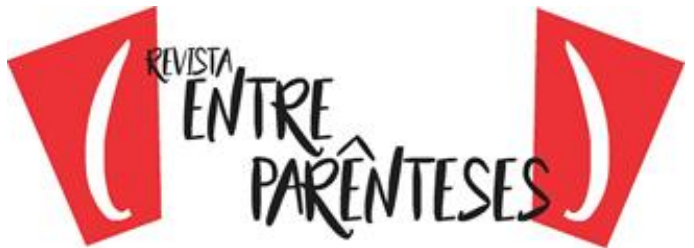

Saúde, Estilo de Vida, Turismo, Esportes, Meio Ambiente, Terceiro Setor e Emigração. Como material adicional para os professores, há uma seção chamada "Dicas e Sugestões" para cada uma das unidades temáticas do LD, que pode ser acessada através do site da editora.

No que diz respeito à quantidade de UFIs, o levantamento feito pode ser conferido no quadro abaixo:

\begin{tabular}{|c|c|}
\hline $\begin{array}{c}\text { Quadro } 1 \text { - Presença } \\
\text { Unidade Temática }\end{array}$ & s no LD Panorama Brasil por unidade tem \\
\hline $01-$ Agronegócios & 19 \\
\hline $02-$ Tecnologia & 5 \\
\hline 03 - Arte \& Cultura & 5 \\
\hline 04 - Saúde & 3 \\
\hline 05 - Estilo de Vida & 6 \\
\hline $06-$ Turismo & 1 \\
\hline 07 - Esportes & 14 \\
\hline 08 - Meio Ambiente & 5 \\
\hline 09 - Terceiro Setor & 1 \\
\hline 10 - Emigração & 10 \\
\hline Total: & 69 \\
\hline
\end{tabular}

A presença de UFls ao longo do livro, como se vê a partir da tabela, apesar de abundante, não é regular. Há unidades temáticas com expressivo número de UFIs, como são as 1,7 e 10 e outras, em que há a ocorrência de apenas $1 \mathrm{UFI}$, como nas unidades temáticas 6 e 9. A quantidade de UFIs, 69 ao total, destaca-se frente a outros livros didáticos de PLE analisados, assim como a escolha da apresentação, na maior parte das vezes, em algum texto.

Sobre as atividades que abordam as UFIs, ao longo das unidades temáticas, há as que favorecem os três momentos de compreensão, retenção e produção de UFIs. As atividades de compreensão que favorecem os recursos atencionais do aluno sendo as de maior frequência. Atividades que favorecem a retenção e produção de UFIs sendo mais raras.

Apesar de ter sido feita a análise de todas as unidades temáticas do $L^{8}{ }^{8}$ em questão, em se tratando de um artigo, por suas limitações de espaço, serão

\footnotetext{
${ }^{8} \mathrm{~A}$ análise de todas as unidades as UFIS do LD "Panorama Brasil", bem como a discussão teórica completa que embasa este artigo, podem ser conferidas na Dissertação de Mestrado intitulada 


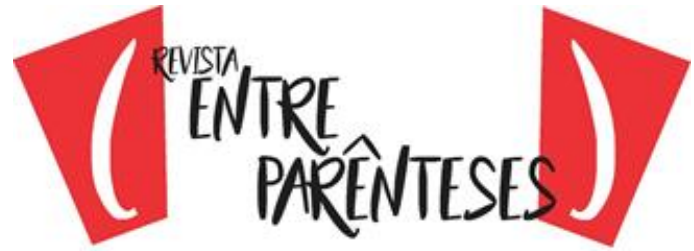

expostas aqui a análise de apenas uma unidade. Abaixo, encontra-se detalhada a presença das UFIs nos textos e nas atividades da unidade temática 3 do LD'9

A terceira unidade, cujo tema é Arte e Cultura, possui 9 textos, dos quais 2 contam com a presença de UFIs. Dentre as 19 atividades, 2 têm UFIs. No total, foram identificadas 5 UFIs, abaixo elencadas, contextualizadas e discutidas.

\begin{tabular}{|c|c|c|c|c|c|c|c|}
\hline \multicolumn{8}{|c|}{ Tabela Resumitiva - Unidade 3 } \\
\hline Unidade & Tema & $\begin{array}{c}\text { Qtd. } \\
\text { Textos* }\end{array}$ & $\begin{array}{c}\text { Textos } \\
\text { com UFls }\end{array}$ & $\begin{array}{c}\text { Textos } \\
\text { sem UFls }\end{array}$ & $\begin{array}{c}\text { Qtd. } \\
\text { Atividades }\end{array}$ & $\begin{array}{c}\text { A. com } \\
\text { UFls }\end{array}$ & $\begin{array}{c}\text { A. sem } \\
\text { UFls }\end{array}$ \\
\hline 3 & $\begin{array}{c}\text { Arte e } \\
\text { Cultura }\end{array}$ & 9 & 2 & 7 & 19 & 2 & 17 \\
\hline
\end{tabular}

\begin{tabular}{|c|l|}
\hline \multicolumn{2}{|c|}{ Tabela de UFIs - Unidade 3 } \\
\hline Unidade Temática & \multicolumn{1}{c|}{ Relação de UFIs } \\
\hline \multirow{3}{*}{ ARTE E CULTURA } & $\begin{array}{l}\text { Pontos fortes; } \\
\text { Arrumar trabalho; } \\
\text { Ganhar as mesas; } \\
\text { Ser uma onda; } \\
\text { Voltar à raiz. }\end{array}$ \\
\hline
\end{tabular}

As UFIs "pontos fortes" e "arrumar trabalho" aparecem pela primeira vez no livro em uma atividade (n. 3) cuja proposta é a de que o aluno reúna frases soltas em um texto coerente. As frases dizem respeito a uma série de etapas elencadas por um determinado sujeito para galgar sucesso em um planejamento para a sua vida. No texto a ser elaborado, os pontos fortes do candidato devem ser realçados. Para a realização da atividade, saber o que são pontos fortes é um pré-requisito.

Em outras línguas, há combinações de lexias para referir-se ao sentido dessa UFI, porém nem todas são análogas ao do português. Em línguas neolatinas como o espanhol, a forma assemelha-se a do português: puntos fuertes e puntos fracos. Assim como no italiano: punti di forza e punti di debolezza; no francês: les point forts e les point faibles e no romeno: punctele forte e punctele slabe. No inglês, porém,

\footnotetext{
"Unidades Fraseológicas Idiomáticas a dar com pau no livro didático 'Panorama Brasil'". Disponível em: https://repositorio.ufsc.br/xmlui/handle/123456789/172258 Acesso em: 05 fev. 2019.

${ }^{9} \mathrm{O}$ capítulo 3 foi escolhido estar mais de acordo com os limites reservados a este tipo de produção científica.
} 


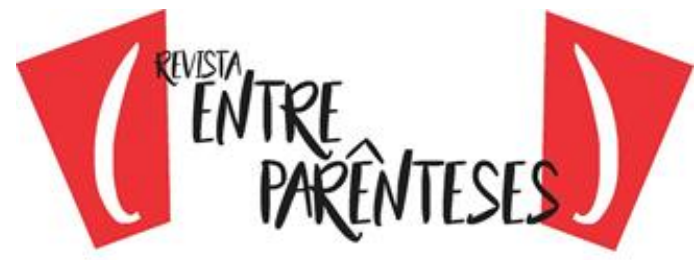

a dualidade pontos fortes e pontos fracos é feita em termos de strengths and weakenesses. Está ausente, portanto, a referência a "pontos", dificultando a transparência para quem parte de línguas germânicas para a compreensão da UFI. Estão em questão nesse caso forças e fraquezas, simplesmente. Por haver certa correspondência, essa colocação pode ser mais facilmente compreendida por um aluno que conhece línguas neolatinas. Sugere-se, portanto que, aos que não possuem conhecimentos de outras línguas latinas, a UFI deve ser explicada. Essa orientação é derivada de García (2003), para o qual, as línguas maternas dos alunos devem ser consideradas. A posição de Garcia (2003) deriva da perspectiva contrastiva que se preocupa em fornecer estruturas do contexto da língua-alvo atentando aos momentos em que a tradução literal pode comprometer a comunicação. Amplia-se o entendimento de que é recomendável ao professor considerar não apenas a língua materna, mas também as outras línguas de que os alunos têm conhecimento, para que utilizar esses recursos como auxiliares à aprendizagem.

Pode-se dizer que a estratégia das autoras do LD, ao colocar em evidência a colocação pontos fortes, 'exige', para o pleno desenvolvimento da atividade, um esforço para a compreensão do que essa unidade léxica quer dizer. Um lugar de destaque é colocado para esses itens léxicos, demonstrando a importância do ensino de UFIs que parece ter para as autoras do material.

Neste caso, o aprendiz é colocado, indiretamente, na situação de ter que desenvolver recursos atencionais e de associação para realizar a atividade. Assim, responderia aos critérios elencados por Channel (1988), no encorajamento do aluno a fazer as próprias associações; também aos ressaltados por Lahuerta e Pujol (1993, 1996), ao sugerirem um meio de favorecer a memorização sem a solicitação explícita do professor ou da atividade e, também, ao favorecer o uso significativo; da mesma forma, atenderia às sugestões de McCarthy (1990), ao propiciar a apresentação da unidade léxica em meio a informações contextuais necessárias para o uso adequado da unidade e de Pavlenko (2009), ao estimular o uso de transferências positivas, no caso de aprendizes que conheçam línguas neolatinas que possam associá-las a aprendizagem do português. 


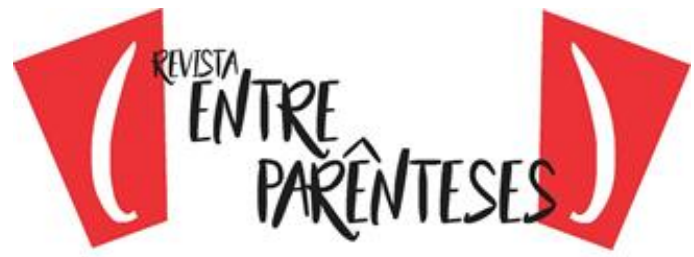

Na seção "Dicas e Sugestões" (PONCE; BURIM; FLORISSI, 2006b, p. 1), as autoras sugerem que, após a realização dessa atividade, sejam dados exemplos de pessoas famosas que tiveram trajetórias difíceis e, em seguida, fornecem um link para a história de Sílvio Santos. Logo, sugerem outra questão para ser discutida: "Darse bem na vida é questão de sorte? O que é dar-se bem na vida?". Neste momento, a autora introduz uma UFI que será retomada novamente na última unidade temática do livro. A retomada é bastante favorável, porém, não fica claro na sistematização porque o resgate desse conhecimento foi escolhido para ser feito 7 unidades após 0 primeiro contato com ela. Do ponto de vista do favorecimento da memorização não se encontram sugestões de autores que justificassem a conveniência de tal escolha, tendo em vista que as repetições são recomendadas em momentos próximos ao do primeiro contato, quando as informações ainda estariam disponíveis na memória de curto prazo para entrarem em redes mais sólidas na memória.

A outra atividade, refere-se a um texto intitulado "Iguaria Regional Vence Barreira Geográfica e Vira Destaque em Restaurantes do Rio e SP" (PONCE; BURIM; FLORISSI, 2006a, p. 35). O texto versa sobre a tapioca, um produto derivado da mandioca que, vendida a preços populares na região Nordeste, tornou-se prato sofisticado em restaurantes refinados do Sudeste do país (RJ e SP). No texto, a UFI ponto forte aparece, novamente, na apresentação do texto: "um ponto forte para se conhecer a cultura de um país é sempre conhecer a sua culinária" (PONCE; BURIM; FLORISSI, 2006a, p. 35) (grifo meu). Aqui, o emprego da UFI faz referência a algo abstrato, a uma experiência e não a qualidades individuais, como na atividade anterior. O sentido é variado e essa escolha oportuniza a formação de novas relações de sentido, bem como maior chance de fixação na memória de longo prazo. Na seção "Dicas e Sugestões" (PONCE; BURIM; FLORISSI, 2006b, p. 2) não há sugestões sobre o uso desta UFI. Considera-se que a inserção da UFI com o sentido alargado mereceria uma atenção por parte do aluno, para que tenha a chance de fixar a extensão do significado. Além disso, a apresentação de perguntas associadas ao tema em discussão que contenham essa UFI pode ser também uma alternativa favorável: ex.: "Qual país que você visitou em que o ponto forte era a culinária?”, "Qual é o ponto forte do seu país em termos gastronômicos?" entre outras. Enfim, sugere- 


\section{("Wîtrer}

se ao professor apresentar mais possibilidades de utilizar a UFI: como referência a um indivíduo, a um país, a uma experiência ou evento (uma viagem, um filme), a um lugar (um hotel, um parque aquático) etc. A aprendizagem implícita é, sem dúvida, uma estratégia interessante, porém, no caso exposto, o material didático poderia ter oferecido melhor apoio ao professor, antecipando a escolha feita pelos dois usos possíveis da UFI - em relação a indivíduos e a fenômenos. Assim, maiores seriam as chances de favorecer a aprendizagem efetiva e de não confundir o aprendiz, em especial, aqueles em cujas línguas não ocorre essa variação sintática. Por fim, o professor pode valer-se dessas observações para complementar o material da forma que achar mais conveniente.

Com relação ao corpo do texto, a UFI ganhar as mesas aparece referindose à tapioca e a UFI ser uma onda aparece de modo bastante claro, com um aposto explicativo em seguida: "Não é uma onda, uma coisa temporária (...)" (PONCE; BURIM; FLORISSI, 2006a, p. 35). A UFI vir para ficar aparece em frase similar à encontrada no capítulo anterior sobre a indústria automobilística "à brasileira": "a tendência veio para ficar". Neste caso, referindo-se à presença do produto popular no Nordeste que ganha as mesas de restaurantes "chiques" do Sudeste do país.

Nesta situação, o contexto parece favorecer a compreensão das UFIs, bem como a escolha das mesmas, por possuírem um grau de transparência considerável. Em se falando de comida, dizer que um prato ganhou as mesas pode ser compreensível. Dizer que algo não é uma onda e, em seguida, dizer que "não é temporário", valendo-se da sinonímia, também é de entendimento possível a partir de inferências. Porém, o que pode ser útil à compreensão, nem sempre é determinante na aprendizagem. Como um primeiro passo, segundo os critérios dos autores que embasam esse estudo, as situações descritas quanto a essas três últimas UFIs estão de acordo com os estudos sobre o momento de compreensão lexical, sendo coerentes e interessantes. No entanto, para que as unidades léxicas não fiquem apenas no vocabulário passivo do aprendiz, será necessário que haja momentos outros de contato variado com as UFIs para a retenção dos conceitos a elas referentes no léxico mental (DURÃO; ANDRADE, 2009; GARCíA, 2003; LAHUERTA; PUJOL, 1993, 1996). 
No caso do texto 4, que se refere a uma propaganda de restaurante em formato de cordel, a UFI voltar à raiz aparece no sexto verso da primeira estrofe. Também aqui, o contexto parece favorecer a compreensão da UFI transparente voltar à raiz, ainda que não haja nenhuma atividade que favoreça o aprendizado da unidade léxica em questão. Para maior contextualização, as autoras sugerem no material "Dicas e Sugestões" (PONCE; BURIM; FLORISSI, 2006b, p. 4) uma série de informações adicionais sobre a região do restaurante e sobre a literatura de cordel, o que parece favorecer o entendimento do que seja voltar à raiz, ainda que de forma indireta, por fazer referência a um aspecto tradicional da cultura popular nordestina:

"A criatividade é fator essencial dos profissionais de Marketing. É comum, contudo, depararmos com idéia (sic) imbatíveis, desenvolvidas por pessoas que nem sempre têm estudos específicos na área. Veja o Cardápio em Cordel do restaurante potiguar Bocoió:

\author{
NOSSO CARDÁPIO EM CORDEL




\section{("tither}

\section{DISCUSSÃO}

A análise da terceira unidade temática "Arte e Cultura", exposta acima, pode ser considerada uma amostra do que se encontra no corpo do LD. Em linhas gerais, o material não apresenta sistematicidade na escolha nem na distribuição de UFIs por capítulo. Porém, o contrário ocorre com relação a como aparecem para o aluno. Em geral, inseridas em textos ou atividades com distintos desenhos, favorecem a compreensão e estimulam a autonomia do aprendiz no uso dos próprios recursos atencionais, predispondo suas redes cognitivas à realização de novas associações. Apesar de esta ser uma das condições de memorização, como demonstra o aporte teórico, somente ela não é suficiente para a retenção na memória de longo prazo. São necessários outros momentos que facilitem a apreensão, o reconhecimento e a produção, completando, assim, o ciclo de aprendizagem de novas lexias. Além disso, a escolha de UFIs transparentes está de acordo com as sugestões dos autores.

Ressalta-se a sensibilidade das autoras ao optar por inserir esse tipo específico de lexia, as UFIs em contexto por favorecer a dedutibilidade do conteúdo devido ao contorno semântico que delimita o universo interpretativo do aprendiz. E ainda, quanto à escolha dos conteúdos relacionados a temas de interesse do públicoalvo do LD, decisão que contribui para a formação de conhecimentos culturais sobre o uso do léxico em português no Brasil. Por este e outros motivos, o LD "Panorama Brasil: português do mundo dos negócios" tem se destacado do cenário dos livros destinados ao ensino do português a estrangeiros.

\section{CONCLUSÃO}

Após as análises realizadas, concluiu-se que o propósito das autoras de apresentar o material através de temas relativos ao mundo dos negócios e de salientar o vocabulário utilizado pelo brasileiro foi alcançado no que diz respeito às UFIs, com uma dedicação ao desenho de um livro que traz uma base potencial para o ensino desses itens léxicos. De forma complementar, sugere-se que mais atividades sejam 


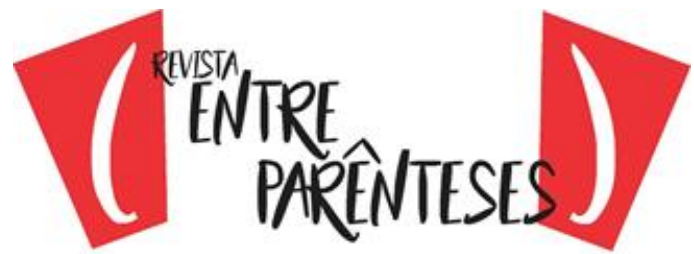

realizadas para favorecer a memorização a longo prazo desses itens lexicais, aproveitando o que o LD já oferece: a inserção das UFIs em campos semânticos, em textos e em abundância no material. Assim, o aprendiz poderia passar da “apresentação" para a "retenção" e "produção" dessas lexias, aumentando seu léxico mental.

Claro está que nenhum material carrega a perfeição, assim como nenhuma teoria ou método, a certeza da aprendizagem. Desta forma, sempre será preciso contar com um ambiente favorável de ensino-aprendizagem: um professor preparado, disposto e um aluno motivado, para que, munidos de um mesmo propósito, possam alcançá-lo. Para facilitar essa "chegada" é que foi realizada esta pesquisa, cuja base epistemológica serve não apenas ao ensino de UFIs, podendo ser aplicada ao ensino do vocabulário de modo geral.

\section{REFERÊNCIAS}

AITCHISON, J. Words in the mind: an introduction to the Mental Lexicon. 4th ed. London: Wiley-Blackwell, 1987.

BAKHTIN, M. Marxismo e filosofia da linguagem: problemas fundamentais do método sociológico na Ciência da Linguagem. 14. ed. São Paulo: Hucitec, 2010.

CHANNELL, J. Psycholinguistic considerations in the study of L2 vocabulary acquisition. In: CARTER, R.; McCARTHY, M. Vocabulary and language teaching. Longman: London, 1988. p. 83-96.

CHOMSKY, N. Linguagem e mente: pensamentos atuais sobre antigos problemas. Brasília: Editora da Universidade de Brasília, 1998.

CUTLER, A. Lexical complexity and sentence processing. In Flores d'Arcais and Jarvella, 1983.

DURÃO, A.; EL-HASSANI, S. ¿Cómo errrores 'artificialmente' propuestos pueden concienciarnos sobre una de las dificultades típicas de aprendices de español? In: DURÃO, A.; ANDRADE, O. (Orgs.) Vários olhares sobre o espanhol: considerações sobre a língua e a literatura. Londrina: Moirá, 2005. p. 113-128.

DURÃO, A.; ANDRADE, O. Seguindo as pistas dos desvios léxico-semânticos produzidos por estudantes brasileiros de espanhol. In.: Por uma lexicografia bilíngue contrastiva. Londrina: EDUEL, 2009. p. 23-43 


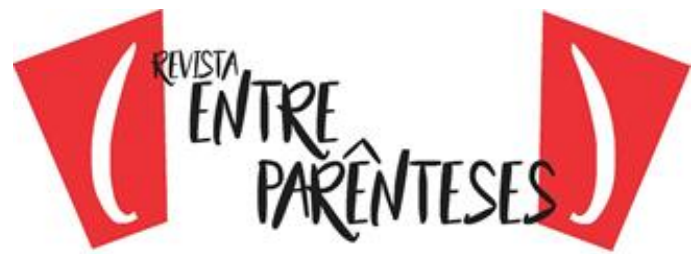

GARCíA, R. Fraseologia en el aula de español: aplicación didáctica de un glosario. In: ASENCIO, J.; LOBATO, J. (Orgs.). Forma, formación de formadores: léxico, fraseologia y falsos amigos. p. 29-64, Madrid: SGEL, 2003.

GAIRNS, R.; REDMAN, S. Working with words: a guide to teaching vocabulary. Australia: Cambridge University Press, 1986.

GIBBS, R. W.; GONZÁLES, G. P. Syntactic frozeness in processing and remembering idioms. Cognition 20 (3): 243-259. 1985.

GURILLO, L. Ruiz. Un enfoque didáctico de la fraseología española para extranjeros. Especulo [on-line]. 2000. Disponível em: http://www.ucm.es/info/especulo/ele. Acesso em: 12 abr. 2016.

LAHUERTA, J.; PUJOL, M. La enseñanza del léxico: una questión metodológica. In: Didáctica del español como lengua extranjera, Madrid: Fundación Actilibre, 1993.

. El lexicón mental y la enseñanza del vocabulario. In SEGOVIANO, Carlos. La enseñanza del léxico español como lengua extranjera. Madrid: Iberoamericana, 1996.

McCARTHY, M. Vocabulary. New York: Oxford University Press, 1990.

MENDES, E. Por que ensinar língua como cultura? In: SANTOS, P.; ALVAREZ, M. L. O. Língua e cultura: no contexto de português língua estrangeira. Campinas, SP. Pontes, 2010. 53-77.

PAVLENKO, A. Conceptual representation in the bilingual lexicon and second language vocabulary learning. In: PAVLENKO, Aneta (ed.) The bilingual mental lexicon: interdisciplinary approaches. Clevedon, UK: Multilingual Matters, 2009, p. 125-160.

PENADÉS MARTINEZ, I. La enseñanza de las unidades fraseológicas. Madrid, Arco Libros. 1999.

PONCE, H; BURIM, S., FLORISSI, S. Panorama Brasil: ensino do português do mundo dos negócios. São Paulo: Galpão, 2006a.

PONCE, H; BURIM, S., FLORISSI, S. Panorama Brasil: ensino do português do mundo dos negócios. Arte e Cultura. São Paulo: Galpão, 2006b.

REIS, N. Unidades fraseológicas idiomáticas a dar com pau no livro didático "Panorama Brasil". 2016. 178f. Dissertação (Doutorado em Linguística) - Programa de Pós-Graduação em Linguística, PPGLin, Florianópolis, 2016. 
SILVEIRA, J. Dicionário de Expressões Populares da Língua Portuguesa: riqueza idiomática das frases verbais uma hiperoficina de gírias e outros modismos lusobrasileiros. São Paulo: Martins Fontes, 2010.

SWINNEY, D. A.; CUTLER, A. The access and processing of idiomatic expressions. Journal of Verbal Learning and Verbal Behavior. n. 18, p. 523-534, 1979.

Recebido em: 25/09/2018.

Aceito em: 04/02/2019. 